\title{
IFRS adoption and firms' opacity around the world: what factors affect this relationship?
}

\author{
Samuel Mongrut \\ Tecnologico de Monterrey, EGADE Business School, \\ Mexico and Universidad del Pacifico, Lima, Peru \\ Manuel Tello Marín and Maria del Carmen Torres Postigo \\ Banco de Credito del Peru, Lima, Peru, and \\ Darcy Fuenzalida O'Shee \\ Departamento de Industrias, Universidad Tecnica Federico Santa Maria, \\ Valparaiso, Chile
}

\begin{abstract}
Purpose - This paper aims to identify what are the moderating factors affecting the relationship between firms' adoption of international financial and reporting standards (IFRS) and the firm's opacity.

Design/methodology/approach - This study uses the meta-analysis methodology from Hunter et al. (1982) to find if the mere IFRS adoption reduces firm's opacity and a meta-regression from Stanley and Jarrell (1989) to identify the moderating factors that may influence this relationship.

Findings - Contrary to previous studies, this study finds a low, negative and nonsignificant correlation between IFRS adoption and firms' opacity, but this relationship depends on the geographical region. Using 34 results from 28 studies from different continents published between 2005 and 2018 this study finds that IFRS adoption reduces opacity in countries with common law (COML) and with more authorities' oversight and power to enforce the rules.

Originality/value - This study finds two institutional commonalities between different previous studies that intend to assess the impact of the IFRS adoption upon firms' opacity: the legal system and the authorities' oversight power.
\end{abstract}

Keywords Earnings management, Opacity, IFRS

Paper type Research paper

\section{Introduction}

Since 2001, a growing number of countries around the world have been adopting the international financial reporting standards (IFRS), so by the end of 2018 more than 120 countries have adopted them (Fuad et al., 2019). This increase in the adoption of IFRS is

(C) Samuel Arturo Mongrut, Manuel Tello Marín, Maria del Carmen Torres Postigo and Darcy Fuenzalida O'Shee. Published in Journal of Economics, Finance and Administrative Science. Published by Emerald Publishing Limited. This article is published under the Creative Commons Attribution (CC BY 4.0) licence. Anyone may reproduce, distribute, translate and create derivative works of this article (for both commercial and non-commercial purposes), subject to full attribution to the original publication and authors. The full terms of this licence maybe seen at http:// creativecommons.org/licences/by/4.0/legalcode

IFRS adoption and firm's opacity

Received 19 February 2020 Revised 13 June 2020 22 July 2020 Accepted 18 April 2021

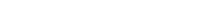


JEFAS 26,51

supposed to bring along reduced earnings manipulation as it provides a regulatory framework for standardizing financial reports and thus brings transparency (Bozkurt and Öz, 2013). Nevertheless, there are firms' financial reports that still reveal earnings management even after the IFRS adoption.

Earnings management $(E M)$ is the act of manipulating discretionary accounting items to show certain desirable results. Its application produces a lack of transparency in the company's financial information also called opacity. Opacity in turn generates asymmetric information between managers and the company's incumbent stakeholders (i.e. shareholders, creditors, regulators, among others) and may induce them to make bad decisions and to establish wrong relationships with the company. This manipulation is favored by the flexibility of the accounting standards and the short scope of the audit for compliance with these standards (Healy and Wahlen, 1999; Bhattacharya et al., 2003). Also, managers may have a part in this, as it is believed that IFRS adoption may act as a substitute for auditors (Mongrut and Winkelried, 2019).

Hence, our first research question is whether the mere adoption of IFRS by companies actually reduces the opacity (i.e. EM) in its accounting and financial reporting? A recent meta-analysis study by Ahmed et al. (2013) conclude that there is a positive, but not significant relationship and this result was because companies in emerging markets have poor accounting structures, and the mere adoption of the IFRS does not guarantee better information transparency.

We expand the sample of Ahmed et al. (2013) by using 36 results out of 23 studies that investigate the impact of IFRS adoption on firm's opacity published between 2005 and 2018 and find that this relationship has a negative and nonsignificant correlation as opposed to the previous study that found a positive and nonsignificant correlation. More importantly, this relationship changes depending on the context.

Our second research question is related to the context: what are the moderating factors playing a role in generating poor accounting structures (i.e. external factors that may influence the relationship between IFRS adoption and firm's opacity)? We use a metaregression from Stanley and Jarrell (1989) to identify moderating factors that mediate the relationship between the IFRS adoption and the firms' opacity.

We identify that the use of common law (COML) in a given country and the authorities' ability to enforce the regulation (rule-of-law) help to reduce a firm's opacity, while the mere IFRS adoption does not have any effect on it.

There is plenty of research about mediating factors at the country level or geographical region. Recently, Öz and Yelkenci (2018) studied the impact of legal origin upon EM in 14 countries and found that a civil law (CIVL) tradition imposes a constraint upon accrual EM, and COML imposes a constraint upon real EM. Mazzi et al. (2018) studied the effect of corruption and Schwartz bipolar cultural dimensions upon IFRS goodwill disclosure requirements in 16 European countries and found that they have significant influence. Recently, El-Helaly et al. (2020) investigated 89 non-European countries and found that the country level of corruption is negatively associated with the extent of IFRS adoption. Hence, legal origin, corruption and cultural aspects do play a role.

In a COML framework, the role of the judge is key in establishing a precedent when resolving a specific legal dispute. Meanwhile, in a CIVL framework, there are statutes and specific codes that guide the judge's decision, so the role of academics is key to determining the rules that will be in the statutes (La Porta et al., 2008). Hence, what happens usually in emerging countries subject to CIVL is lobbying and bribery to obtain a certain desirable sentence. 
According to a recent literature survey conducted by De George and Shivakumar (2016), there are two main problems across the different studies that study the impact of IFRS adoption into different variables of interest (including opacity):

- authors do not agree on whether the observed results are due to IFRS adoption or other institutional changes that occur at the same time; and

- it is difficult to make cross-study comparisons because of the different empirical choices made by authors.

Our contribution lies precisely in finding a common result between different authors concerning the institutional context. Using a meta-regression, we find that IFRS adoption reduces opacity in countries with COML and with more authorities' oversight and power to enforce the rules. Furthermore, to achieve this result, we consider the different empirical choices made by authors, especially the sample size, and found that it matters.

Section 2 reviews the relevant literature on the relationship between IFRS adoption and firms' opacity. Section 3 presents the two methodologies that we use to get our results: metaanalysis and meta-regression, while in Section 4 discusses our results. Section 5 concludes.

\section{International financial and reporting standards adoption and firms' opacity}

We consider 52 studies where 24 of them favored a positive relationship between the IFRS adoption and the reduction of firm's opacity, and 28 did not conclude that there was a positive relationship or concluded that the relationship was negative. Given the higher proportion studies (54\%) that favor that the mere adoption of IFRS has no effect or increases firm's opacity we establish the following hypothesis:

H1. The relationship between the IFRS adoption and firm's opacity is positive and significant.

Given these divided results between different authors, it is interesting to determine what factors are affecting these results: are they geographic? Or institutional? In what follows, we first review literature related to the different regions and then to the institutional factors.

The adoption of IFRS by the European Union (EU) began in 2003, becoming mandatory as of 2005. Callao and Jarne (2010) conducted a study on 1,408 nonfinancial listed firms in the EU and found that the use of discretionary accruals increased after IFRS adoption. Recently, Cereola et al. (2017) found that IFRS 8 adoption resulted in a significant number of companies reporting disaggregated revenues at the individual country level in companies from Europe, Australia and New Zealand.

According to Timm et al. (2016), EM is greater in Latin American firms than in continental and Anglo-Saxon European firms, even in the case of Latin American companies listed on US stock exchanges. This reveals that there must be strong incentives in each country for firms not to use discretionary accruals. Accounting standards in China began to converge to IFRS in 2006 and Indonesia in 2012, while in India IFRS standard was adopted from 2016. Wang and Campbell (2012) concluded that IFRS adoption discourages earnings smoothing, but it motivates earnings aggressiveness in accounting reports. Given the abovementioned review, we derive the following hypothesis:

H2. There is a different and significant relationship between the IFRS adoption and a firm's opacity across different geographical regions.

Perafan and Benavides (2017) establish that the legal system of a country significantly influences the effectiveness of IFRS adoption on the quality of financial statements. This
IFRS adoption and firm's opacity 
JEFAS

26,51

10

occurs in those countries where COML exists, as in the UK. Takamatsu and Favero (2017) pointed out that in countries with a French legal system (civil law) it is possible to detect a higher level of earnings smoothing. So, we derive the following hypothesis:

H3. IFRS adoption is more effective in reducing opacity in countries with COML rather than in countries with CIVL.

The government oversight and enforcement power could also be another institutional common factor between previous studies that assess the impact of IFRS adoption on firms' opacity. High oversight and enforcement power can guarantee compliance with the accounting regulations of the country because there is a greater probability that companies will be discovered and penalized if they are not complying with the IFRS adoption. Byard et al. (2011) studied the change in the quality of information after the IFRS adoption from the point of the ability of analysts to make accurate predictions. They found that countries' high oversight power is necessary to reduce prediction errors.

Hence, our last hypothesis is the following:

H4. There is a negative relationship between IFRS adoption and a firm's opacity in countries with higher oversight and enforcement power.

\section{Methodology}

To answer our first research question, we tested the first hypothesis using the meta-analysis introduced by Hunter et al. (1982), and to answer our second research question we tested H2, $H 3$ and $H 4$ using the meta-regression introduced by Stanley and Jarrell (1989).

We collected 67 studies between 2005 and 2018 that investigate the relationship between IFRS adoption and a firm's opacity. The earliest year when the adoption of IFRS became mandatory for companies in all studies was 2005. We consulted several databases, such as Web of Science, SCOPUS, Emerald and Science Direct, using different keywords such as IFRS adoption, EM, opacity, IFRS effects, IAS adoption, discretionary accruals and their combinations.

We then excluded studies that measure EM differently, for example, by the ability of analysts to make predictions or by the probability of incurring in manipulating accounting numbers. Besides, we excluded from the sample studies that did not reveal the countries included in the sample because we needed to associate the country with a certain region, the legal system, and oversight and law enforcement. In the end, we obtained 52 studies that initially were suitable for applying one or both methodologies (the complete list of studies is available from authors on request).

We answered our first hypothesis with the use of the meta-analysis, but with an expanded sample and more controls than the one used by Ahmed et al. (2013). We used 36 results, extracted from 23 studies, which gave us 7 more results (observations) coming from more recent studies. The meta-analysis, first presented by Hunter et al. (1982), is a statistical method that aims to find an underlying common proposition among similar academic studies considering a certain error in each study. Therefore, we aim to obtain a weighted average correlation coefficient $r$ (in our case the correlation between IFRS adoption and firm's opacity) from different studies where the weight could be different (in our case is the sample size of each study).

Our goal in the meta-analysis is to obtain the correlation coefficient $r$ between the dependent variable (EM as a proxy for opacity) and independent variable (IFRS adoption), which is obtained for each pairwise variables of each study. 
If a study does not specify the correlation coefficient but includes other statistics, such as $\mathrm{Z}$ and $\mathrm{T}$ statistics, we can use the following formulas to estimate the correlation coefficient (Rosenthal and Di Matteo, 2001):

$$
\begin{gathered}
r=\sqrt{\frac{t^{2}}{t^{2}+m}} \\
r=\frac{Z}{\sqrt{n}}
\end{gathered}
$$

In the abovementioned equations, $m$ is the degrees of freedom and $n$ is the sample size of the study. Once the correlation coefficient of each study has been obtained, we must obtain the weighted average correlation and the population variance. The weighted average correlation is calculated as follows:

$$
\bar{r}=\frac{\sum N_{i} r_{i}}{\sum N_{i}}
$$

In equation (3) $N_{i}$ y $r_{i}$ are the sample size and the correlation coefficient of the study $i$, respectively. Then, the variance of all the correlation coefficients is calculated as follows:

$$
S_{r}^{2}=\frac{\sum N_{i}\left(r_{i}-\bar{r}\right)^{2}}{\sum N_{i}}
$$

Hunter and Schmidt (2004) indicate that observed variance includes the variance of the error $\left(S_{e}^{2}\right)$ due to statistical factors with the population variance, as is the sampling error. Therefore, the best estimate of the correlation variance would be a residual variance $\left(S_{p}^{2}=S_{r}^{2}-S_{e}^{2}\right)$. Where:

$$
S_{e}^{2}=\frac{\left(1-r^{2}\right)^{2} K}{\sum N_{i}}
$$

In equation (5), $K$ is the number of studies included in the analysis. Finally, we construct a $95 \%$ confidence interval using estimates of $\bar{r}$ and $S_{r}$. If the confidence interval includes 0 , the relevant average correlation represents a nonsignificant population relationship.

A powerful test that evaluates moderating effects consists of determining if the observed variance represents homogeneity or heterogeneity (Ahmed and Courtis, 1999). To do this, we must estimate the chi-square statistic:

$$
X_{K-1}^{2}=\frac{N S_{r}^{2}}{\left(1-\bar{r}^{2}\right)^{2}}
$$

The test that considers the heterogeneous effects of each variable consists of grouping the studies and their calculations of $r$ and $S_{r}^{2}$ per subgroup. This eliminates heterogeneity and identifies the effect more precisely if we have enough studies. After applying the filters, those studies that did not contain the necessary data to calculate the weighted average 
JEFAS

26,51

correlation were excluded from the sample. We came up with 23 studies and 36 results extracted from them.

To answer our second research question and to test $H 2, H 3$ and $H 4$, we used the metaregression analysis. We decided to use the random-effect meta-regression because we could deal with between-study variation (excess of heterogeneity) and add moderator variables in the regression (Stanley, 2001).

Next, we followed the guidelines established by the meta-analysis of economic research network (MAER-NET) to apply the meta-regression (Rosenberg and Rost, 2013). From the total sample of 52 studies, only 28 studies have all the information to perform the metaregression. Finally, we used 34 results from the 28 studies that specifically deal with the effect of IFRS adoption on $E M$.

Publish bias consists of taking only academic publications with significant results and this could contaminate our final results. Hence, we decided to avoid this bias by including academic articles published in well-reputed indexed journals. From the 28 studies, 4 were published in journals that belong to the first quartile of the business areas in SCOPUS, 13 belong to the second quartile, 8 to the third quartile, and 3 to the fourth quartile (Stanley and Jarrell, 2005).

The 34 results that were selected from the 28 studies fulfilled the following requirements:

- earnings management $(E M)$ is the dependent variable and IFRS adoption is the independent variable.

All results must come from models that resemble the following generic regression model:

$$
E M_{i}=\mu+\beta_{i} I F R S_{i}+\beta_{x} \mathbf{Z}_{\mathbf{x}}+\varepsilon_{\mathbf{i}}
$$

Where:

$E M$ = represents a measure of earnings management;

IFRS = usually is a dummy variable that indicates IFRS adoption;

$Z \quad=$ is a vector that includes other explanatory variables; and

$\varepsilon \quad=$ is the error term.

It is important to note that measures of $E M$ in the studies were calculated using different specifications such as the Jones's model (JONM), the absolute accruals model (ABSM), the abnormal accruals of working capital model (AWCA) and the real activities manipulation model (RAM). The first three models intend to estimate the magnitude of discretionary accruals with some differences among them, while the latter model detects real manipulating activities to increase sales, lower the cost of goods sold and increase reported margins:

- All results must include the necessary econometric results to conduct the metaregression analysis.

We excluded studies that present only descriptive statistics and not econometric results. However, if these studies include the estimation of correlation coefficients (i.e. size effects) then they are included in the meta-analysis, but not in the meta-regression. The correlation coefficient is used in the meta-analysis and the beta coefficient is used in the metaregression. All the studies applied a multiple regression approach, so the beta coefficient measures the magnitude of the relationship between EM and IFRS adoption keeping all other variables constant, so it is a marginal effect. 
In the meta-regression, the dependent variable is composed of a vector of beta coefficients coming from 34 results from 28 studies, while independent variables are the constant (H1), studies that involve countries from different regions $(H 2)$, studies that include countries with different legal systems $(H 3)$ and the country degree of oversight and enforcement of regulations or rule-of-law $(H 4)$.

We also used controls such as the type of IFRS adoption, the sample size, the academic quartile of the journal that published the result and the methodology used to measure $E M$ in the studies. The meta-regression is defined as follows for $k=1,2, \ldots, 34$ results of the selected studies:

$$
\begin{aligned}
\beta_{k}= & \mu+\sum_{i=1}^{3} \theta_{i} D D_{i, k}+\sum_{i=1}^{3} U_{i} R_{i, k}+\sum_{i=1}^{3} \delta_{i} L_{i, k}+\sum_{i=1}^{1} \vartheta_{i} R O L_{i, k} \\
& +\sum_{i=1}^{3} \alpha_{i} A d o p_{i, k}+\sum_{i=1}^{1} \gamma_{i} N_{i, k}+\sum_{i=1}^{4} \eta_{i} J_{i, k}+\sum_{i=1}^{5} \tau_{i} M_{i, k}+\varepsilon_{k}
\end{aligned}
$$

Where:

$D D_{i, k}$ is a dummy variable that represents three types of studies: studies that involved developed countries (DC), developing countries (UC) and developed and developing countries in their results $(\mathrm{OC})$.

$R_{i, k}$ is a dummy variable associated with the country of origin of the sample of the $K$ result included in the meta-regression. There are seven categories to indicate the region: EURO, ASIA, AFRICA, OCEANIA, NOAM (North America), SOAM (South America), OTHR (countries from different regions).

$L_{i, k}$ is a dummy variable associated with the legal system of the country of origin of the sample: COML, CIVL and mixture (OTHL). We have four more categories to describe the subfamilies: French civil law (FREL), Scandinavian civil law (SCAL), Germanic civil law (GERL) and socialist civil law (SOCL).

$R O L_{i, k}$ it is a variable associated with the oversight and the degree of compliance with the regulations that exists in the country of origin of the sample. We use the Rule-of-Law Index of the World Justice Project 2017-2018 that measures the adhesion of a country to its laws considering 44 indicators organized around eight main factors: government's power restrictions, absence of corruption, the opening of the government, presence of fundamental rights, order and security, compliance with regulations, civil justice and criminal justice.

We constructed $R O L_{i, k}$ as a deviation of the Rule of Law Index assigned to the country in question (value between 0 and 1) concerning the average of the indexes of the observations included in the meta-regression to guarantee that the constant $(\mu)$ represents the average effect of IFRS adoption on firm's opacity.

$A d o p_{i, k}$ is a dummy variable associated with the type of IFRS adoption in the country of origin of the sample: voluntary IFRS adoption (VADOP), mandatory (MADOP) and other (OTHA). The last category includes results of a mixture of countries where both voluntary and mandatory adoption co-exist because compulsory adoption applies to the subset of usually listed companies.

$N_{i, k}$ : is a variable associated with the sample size and takes the value $\left(n_{k}-\bar{n}\right)^{\frac{1}{3}}$ where $n_{k}$ is the sample of the result $k$ and $\bar{n}$ is the average of samples of all the results (observations)
IFRS adoption and firm's opacity 
JEFAS

26,51

included in the meta-regression. Deviations from the mean are used to ensure that the constant $(\mu)$ really represents the average effect of IFRS adoption on EM or opacity.

$J_{i, k}$ is a dummy variable that can take four categories $J$ and four categories $Q$. $J$ is related to the main subject of the journal: accounting (J1), economics (J2), business (J3) and other (J4), and $Q$ is related to the journal's quartile in SCOPUS: Q1, Q2, Q3 and Q4.

$M_{i, k}$ is a dummy variable associated with the methodology used to estimate $E M$ in the result $K$. This variable has five categories: JONM, ABSM, AWCA model, RAM model and another model (OTHM).

\section{Results}

The meta-analysis was conducted according to the methodology of Hunter et al. (1982) included 36 results from 23 studies. It should also be indicated that 25 results use a sample from Europe, 6 from Asia, 3 from Oceania, 1 from North America and 1 is a group of countries that belong to more than one region. Table 1 shows the results of the metaanalysis. The general result is that there is a negative, low and nonsignificant correlation between IFRS adoption and EM, which differs from that presented by Ahmed et al. (2013) because they found a positive and not significant result. However, the meta-analysis does not allow us to conclude that the IFRS adoption o is associated with fewer EM. This result is robust even when using moderating factors such as the type of adoption.

Considering the geographical regions, we were able to find evidence of a negative and significant effect upon EM only in the case of Europe, but not in the other regions. Hence, firms in Europe are less engaged with EM practices than in other regions. Furthermore, we find that greater oversight power and law enforcement are related to fewer $E M$.

This result is quite the opposite to the one obtained by Ahmed et al. (2013) because they have found a positive and significant relationship between IFRS adoption and EM in countries with a higher Rule-of-Law Index.

Our descriptive statistics (not reported) of the entire sample corresponds to the 34 results used in the meta-regression. We used 13 results belonging to Europe, 10 to Asia, one to Oceania, 2 to North America, 2 to Latin America and one to Africa, while the rest of the studies use mixed samples. The average sample of the total firm-year observations is 7,309, with 67 being the minimum and 104,348 the maximum, which indicates that there is a great diversity of sample sizes that must be taken into consideration.

We decided to exclude from our sample the study by Houque et al. (2012) due to the extreme value represented by its sample size $(104,348)$, and the study by Iatridis (2010) due to the extreme value represented by its beta $(-10.6130)$ versus the average of betas of the complete sample (-0.2787), that is, more than five standard deviations. In this sample of 32 studies, without extreme values, we identify that there are 17 results $(\sim 50 \%)$ whose sample contains countries with civil rights, while eight results have samples of countries with common rights. Another seven results are not classified in any of the previous two since they contain different countries with different legal systems.

In addition, we classified our sample by the type of adoption used in each study where two of them contain voluntary adoption and 25 contain firms that were forced to implement IFRS; the rest of the results could not be classified in any of these two groups, so they were in the "other" category.

Our sample with 34 results has obtained an average Rule-of-Law Index of 0.6315 and 0.6259 in the case of our 32 results sample, which shows an average adherence to the law. Likewise, most of the countries have had mandatory IFRS adoption and have used the model stated by Jones (1991) or modified JONM with ABSM to measure EM. 


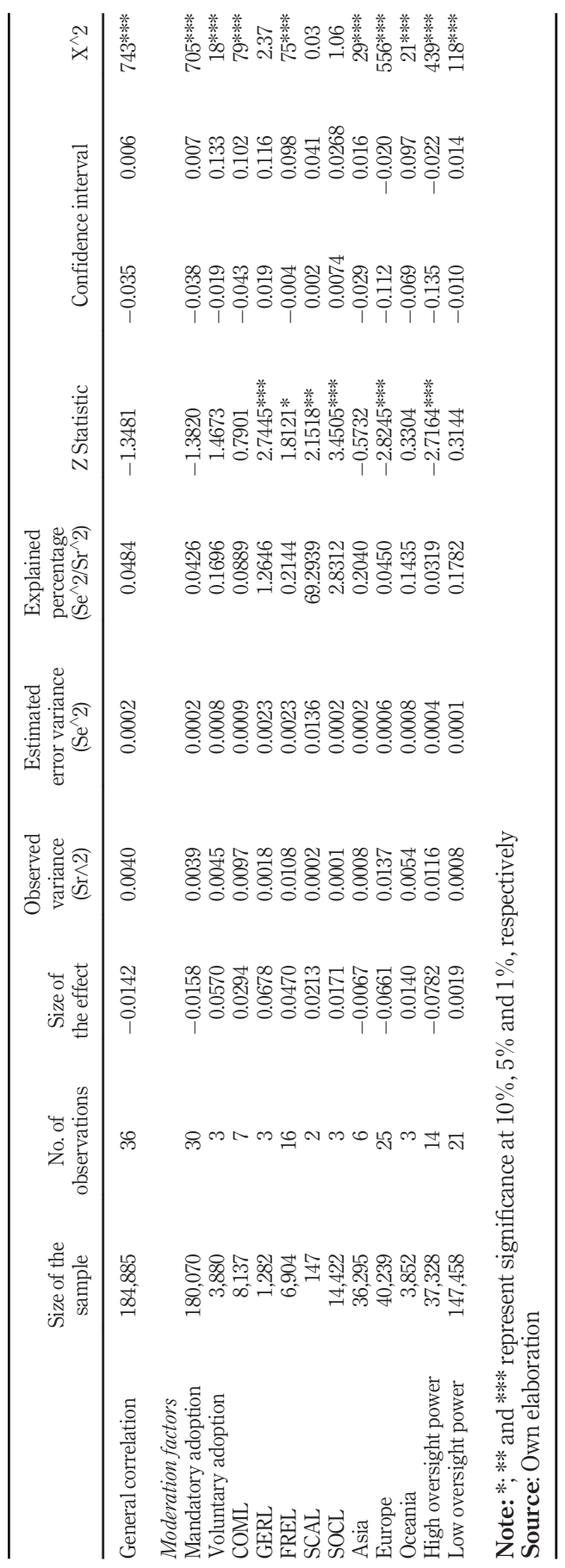

IFRS adoption and firm's opacity

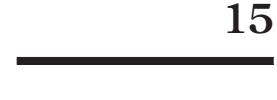

Table 1. Results of metaanalysis 
JEFAS

26,51

16

The first column of Panel A (Table 2) shows the results for the whole sample of 34 results including the two with extreme values. We observe that none of the coefficients are significant due to the presence of extreme values. In the second column of Panel A (Table 2) we show the results for our sample of 32 results without extreme values.

We can observe that, on average, the constant has a value of 0.367 and is significant at $90 \%$. Hence, we verify our first hypothesis because, on average, the IFRS adoption tends to increase opacity, hence we can find a positive and significant relationship whenever we control for moderating variables.

This result could be explained in two different ways: there are some countries where local accounting standards before IFRS adoption were stricter than the situation with IFRS, so it seems that IFRS adoption grants greater flexibility in the accounting practice, so its mere adoption does not guarantee fewer EM. Alternatively, companies are confident in gaining more transparency with the mere adoption of IFRS standards, so they do not hire wellreputed audit companies able to give them advise to achieve even more transparency. Even more, there are countries, such as the United States, where audit companies are forbidden to provide advice when auditing a company.

To obtain robust results, we decided to conduct other regressions using different control variables for the journals and the regions. In the second column of Panel B (Table 2), we find again an average positive and significant effect of IFRS adoption on EM (0.499). Hence, we verify our first hypothesis with different control variables.

Concerning our second hypothesis, we verify that there is a different and significant relationship between firms' adoption and opacity. As opposed to previous studies, we also find a positive and significant effect for the European and the Oceanian regions and a negative and significant effect for Asia and Africa. The former result for Oceania could be due to the small number of observations and the latter result could be due to the existence of firms operating under looser local laws and the IFRS adoption helps them reduce the opacity. Our results show that IFRS adoption has increased EM in Europe, a result that is not aligned with previous evidence (i.e. Burgstahler et al., 2006) that suggests otherwise due to the existence of developed capital markets, diffusely held firms, and good investor protection. Hence, as time goes by, companies are relying more upon achieving transparency just with the mere adoption of IFRS standards, and high-quality auditing companies are less hired (Mongrut and Winkelried, 2019).

Another added value of our study is the negative and significant relationship between IFRS adoption and opacity in COML countries as opposed to CIVL ones. The second column of Panel A (Table 2) indicates a negative relationship when analyzing countries with systems of COML.

The coefficient of the COML variable is negative (-0.443) and significant at $90 \%$, while the coefficient of the variable socialist civil law (SOCL) is positive (1.037) and significant at $95 \%$. In other words, we verify our third hypothesis because the variable "COML" is associated with a negative beta that measures the effect of IFRS adoption on firm's opacity $(0.367-0.443=-0.076)$ than the beta associated with the variable "SOCL" $(0.367+1.037=$ 1.404). We explain that in CIVL countries the possibility to bribe a judge to get a positive sentence is higher rather than in COML countries.

Concerning the type of adoption (mandatory, voluntary or mixed), we find that voluntary IFRS adoption is positive and significant, while a mixed adoption is negative and significant. These results indicate that voluntary IFRS adoption alone does not guarantee the reduction of $E M$, it may even increase it. This result is not consistent with the argument proposed by Christensen et al. (2015) who affirm that firms who voluntarily adopt IFRS suffer from fewer EM because they wish to become more transparent. 


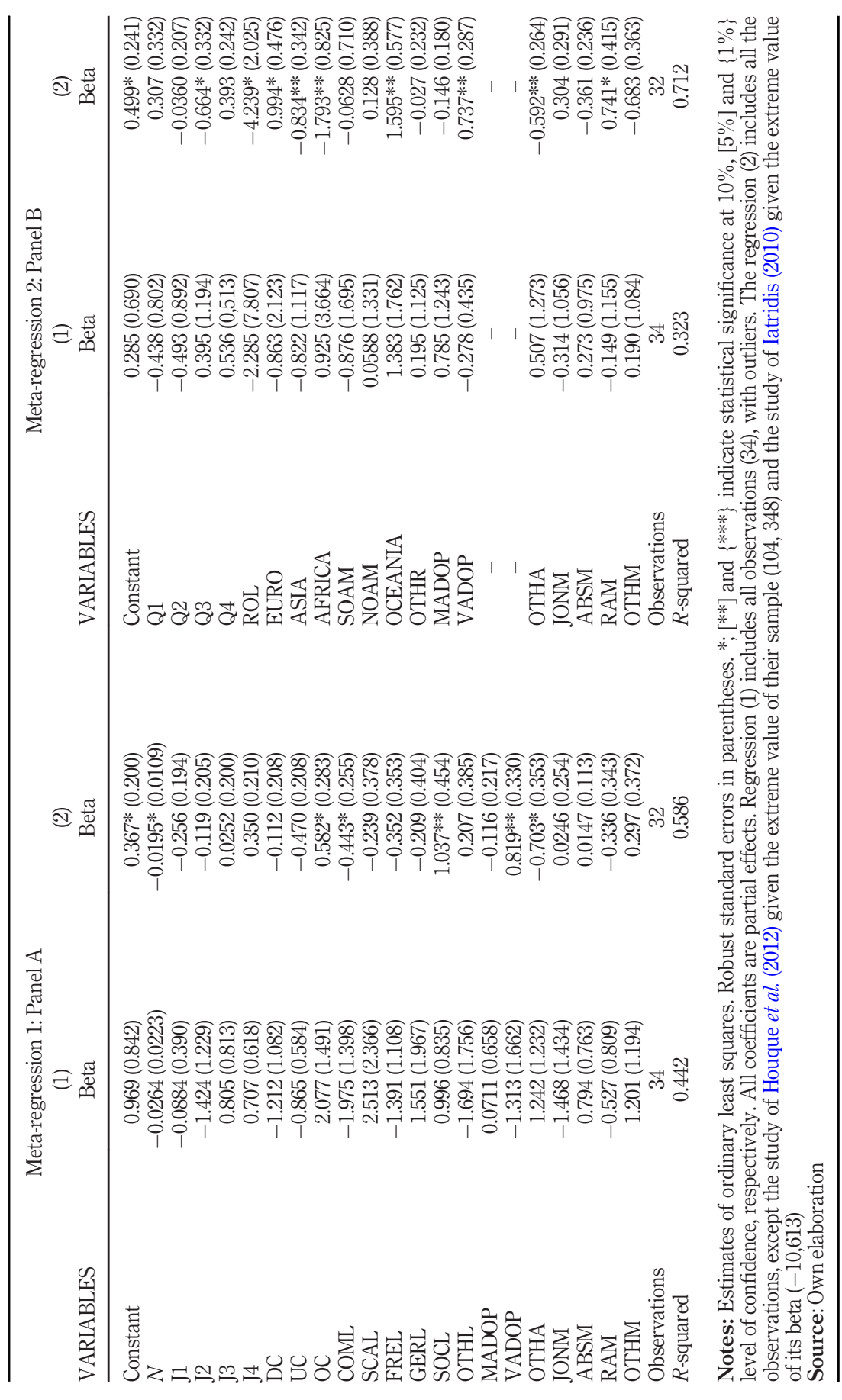

IFRS adoption and firm's opacity

Table 2. Meta-Regressions 1 and 2 
JEFAS

26,51

We were able to verify our fourth hypothesis because we obtain a remarkably high negative and significant coefficient for the rule-of-law equal to -4.239 . This shows that oversight system and enforcement is a relevant factor when studying the effect of IFRS adoption and helps to reduce in a meaningful way EM. This result may play a role jointly with the COML result because in countries with CIVL it would be more difficult to apply a higher rule-of-law due to the high level of corruption. The Rule-of-Law Index includes eight factors and compliance, and regulation is just one of them. Hence, there are many reasons why the ruleof-law may influence the companies' opacity.

Concerning the measurement of $E M$, we found a positive and significant coefficient for the RAM, while other methodologies did not have significant estimators. This shows that when we use the RAM model there is a tendency to estimate positive effects of IFRS adoption on firms' opacity $(+0.741$ above +0.499$)$. This last model focuses on management decisions to change the time or structure of an operation.

\section{Conclusion}

Overall, we cannot conclude that there is a positive or negative relationship between IFRS adoption and firms' opacity. This result is in line with the one of Trimble (2018) who was not able to find a systematic relationship either using a sample of 5,691 firms in 46 countries. We conclude that the impact of IFRS adoption upon firms' opacity depends on the moderating factors: country legal origin and rule-of-law that includes the absence of corruption and some cultural aspects such as power distance (order and security) and individualism versus collectivism (open government).

Hence, the mere IFRS adoption does not guarantee fewer EM. Furthermore, there is a different and significant relationship between the IFRS adoption and firms' opacity across different geographical regions. The IFRS adoption brings more benefits for the more lagged regions in terms of adopting common standards such as Africa and Asia and seems to have no effect in Europe and Oceania where companies are relying more on the reduction of EM due to the mere adoption of the IFRS standard.

In line with Perafan and Benavides (2017) we find that countries with COML rather than CIVL legal systems encourage more transparency, but in all regions rather than in some countries. We believe this happens mainly because in emerging countries it is easier that companies influence the judges' sentences with bribery, so they can obtain favorable results. So, companies may adopt the IFRS standard knowing that if there is a discrepancy, they can get away with their will.

Byard et al. (2011) and Landsman et al. (2012) found that in countries with better oversight and compliance the quality of accounting information was better than in countries with a low rule-of-law in terms of more predictability and lower volatility of stock returns. We find a strong and negative relationship between high rule-of-law and firms' opacity. This means that in countries with a higher degree of oversight and compliance to regulations, the IFRS adoption helps to reduce firms' opacity, and this goes beyond information quality.

Our results involve important theoretical and managerial implications. On a theoretical side, it is particularly important to analyze managers' incentives in a more detailed way depending on the degree of transparency of the company: companies with a low degree of transparency will benefit from the IFRS adoption and companies with a high degree of transparency will not have any effect or the IFRS adoption could go even against more transparency by not hiring high-quality audit firms.

If the country is being dominated by CIVL and a low degree of oversight and enforcement (rule-of-law), managers of companies that have adopted the IFRS standard will 
take for granted its benefits. We believe that to understand better why mere adoption of IFRS standards does not increase transparency we need to contextualize the study to different samples of companies depending on their degree of transparency and depending on the context in which they are operating.

On the managerial side managers from companies who have adopted the IFRS standard should not disregard the information quality and quality of the audit firms they are hiring. It could be less expensive to hire a high-quality audit company rather than to face a company loss due to an informational scandal.

Regulators must give more weight to the information transparency section of such indexes in such a way that the company's loss due to opacity may be high. Instead of restraining high-quality audit companies from advising to their customers about how to improve information transparency, regulators should foster this practice and at the same time penalize severely any collusion activity between audit companies and their clients.

There are several future lines of research, for instance, recently, De Moura and Gupta (2019) found a positive effect between IFRS adoption in analysts' information environment, but it remains to analyze whether there is also an improvement in the analysts' consensus forecast. Furthermore, De Moura et al. (2020) also found that IFRS adoption reduced the firm's cost of equity and its cost of debt, but we may wonder whether the country risk will be also affected by this IFRS adoption.

There are many possible ways in which the rule-of-law may influence the companies' level of opacity, those especially linked to cultural dimensions and its power to enforce the disclosure of risky activities (Adam-Müller and Erkens, 2020). So, future research would benefit by disentangling this factor into its several components. It would be interesting to study whether a heavily regulated industry yields higher information transparency rather than a non-heavily regulated industry. Future studies may help us to elucidate these and other interesting questions.

\section{References}

Adam-Müller, A.F. and Erkens, M.H. (2020), "Risk disclosure noncompliance", Journal of Accounting and Public Policy, Vol. 39 No. 3, p. 106739.

Ahmed, K. and Courtis, J.K. (1999), "Associations between corporate characteristics and disclosures level in annual reports: a meta-analysis", The British Accounting Review, Vol. 31 No. 1, pp. 35-61.

Ahmed, K., Chalmers, K. and Khlif, H. (2013), "A meta-analysis of IFRS adoption effects", The International Journal of Accounting, Vol. 48 No. 2, pp. 173-217.

Bhattacharya, U., Daouk, H. and Welker, M. (2003), "The world price of earnings opacity", The Accounting Review, Vol. 78 No. 3, pp. 641-678.

Bozkurt, O. and Öz, Y. (2013), "Perceptions of professionals interested in accounting and auditing about acceptance and adaptation of global financial reporting standards", Journal of Economics Finance and Administrative Science, Vol. 18 No. 34, pp. 16-23.

Burgstahler, D., Hail, L. and Leuz, C. (2006), "The importance of reporting incentives: earnings management in European private and public firms", The Accounting Review, Vol. 81 No. 5, pp. 983-1016.

Byard, D., Li, Y. and Yu, Y. (2011), "The effect of mandatory IFRS adoption on financial analysts' information environment", Journal of Accounting Research, Vol. 49 No. 1, pp. 69-96.

Callao, S. and Jarne, J.I. (2010), "Have IFRS affected earnings management in the European Union?", Accounting in Europe, Vol. 7 No. 2, pp. 59-189.

Cereola, S.J., Nichols, N.B. and Street, D.L. (2017), "Geographic segment disclosures under IFRS 8: changes in materiality and fineness by European, Australian and New Zealand blue chip companies", Research in Accounting Regulation, Vol. 29 No. 2, pp. 119-128.

IFRS adoption and firm's opacity

\section{$-2$}


JEFAS 26,51

Christensen, H.B., Lee, E., Walker, M. and Zeng, C. (2015), "Incentives or standards: what determines accounting quality changes around IFRS adoption?", European Accounting Review, Vol. 24 No. 1, pp. 31-61.

De George, E. and Shivakumar, L. (2016), "A review of IFRS adoption literature”, Review of Accounting Studies, Vol. 21 No. 3, pp. 898-1004.

De Moura, A.A.F. and Gupta, J. (2019), "Mandatory adoption of IFRS in Latin America: a boon or a bias", Journal of International Financial Markets, Institutions and Money, Vol. 60, pp. 111-133.

De Moura, A.A.F., Altuwaijri, A. and Gupta, J. (2020), "Did mandatory IFRS adoption affect the cost of capital in Latin American countries?", Journal of International Accounting, Auditing and Taxation, Vol. 38, p. 100301.

El-Helaly, M., Ntim, C.G. and Al-Gazzar, M. (2020), "Diffusion theory, national corruption and IFRS adoption around the world", Journal of International Accounting, Auditing and Taxation, Vol. 38, pp. 1-22.

Fuad, F., Juliarto, A. and Harto, P. (2019), "Does IFRS convergence really increase accounting qualities? Emerging market evidence", Journal of Economics, Finance and Administrative Science, Vol. 24 No. 48, pp. 205-220.

Healy, P.M. and Wahlen, J.M. (1999), "A review of the earnings management literature and its implications for standard setting”, Accounting Horizons, Vol. 13 No. 4, pp. 365-383.

Houque, M.N., van Zijl, T., Dunstan, K. and Karim, W. (2012), "The effect of IFRS adoption and investor protection on earnings quality around the world", The International Journal of Accounting, Vol. 47 No. 3, pp. 333-355.

Hunter, J.E. and Schmidt, F.L. (2004), Methods of Meta-Analysis: Correcting Error and Bias in Research Findings, Sage Publications, p. 639, ISBN-13: 978-1452286891, doi:10.2307/2289738.

Hunter, J., Schmidt, F. and Jackson, G. (1982), Meta-Analysis: cumulating Research Findings across Studies, Sage Publications, Beverly Hills, CA, p. 176, ISBN-13: 978-0803918641, doi:10.3102/ 0013189X015008020.

Iatridis, G. (2010), "International financial reporting standards and the quality of financial statement information", International Review of Financial Analysis, Vol. 19 No. 3, pp. 193-204.

Jones, J.J. (1991), "Earnings management during import relief investigations", Journal of Accounting Research, Vol. 29 No. 2, pp. 193-228.

La Porta, R., Lopez-de-Silanes, F. and Schleifer, A. (2008), "The economic consequences of legal origins", Journal of Economic Literature, Vol. 46 No. 2, pp. 285-332.

Landsman, W.R., Maydew, E.L. and Thornock, J.R. (2012), "The information content of annual earnings announcements and mandatory adoption of IFRS”, Journal of Accounting and Economics, Vol. 53 Nos 1/2, pp. 34-54.

Mazzi, F., Slack, R. and Tsalavoutas, I. (2018), "The effect of corruption and culture on mandatory disclosure compliance levels: goodwill reporting in Europe", Journal of International Accounting, Auditing and Taxation, Vol. 31, pp. 52-73.

Mongrut, S. and Winkelried, D. (2019), "Unintended effects of IFRS adoption on earnings management: the case of Latin America”, Emerging Markets Review, Vol. 38, pp. 377-388.

Oz, I.O. and Yelkenci, T. (2018), "Examination of real and accrual earnings management: a crosscountry analysis of legal origin under IFRS”, International Review of Financial Analysis, Vol. 58, pp. 24-37.

Perafan, H. and Benavides, J. (2017), "Impact of IFRS on the quality of financial information in the United Kingdom and France: evidence from a new perspective”, Intangible Capital, Vol. 13, pp. 850-878, doi: 10.3926/ic.939.

Rosenberg, R. and Rost, K. (2013), "Reporting guideliness for meta-regression analysis in economics", Journal of Economic Surveys, Vol. 27 No. 2, pp. 390-394. 
Rosenthal, R. and Di Matteo, M. (2001), "Meta-analysis: recent developments in quantitative methods for literature reviews", Annual Review of Psychology, Vol. 52 No. 1, pp. 59-82.

Stanley, T.D. (2001), "Wheat from chaff: meta-analysis as quantitative literature review", Journal of Economic Perspectives, Vol. 15 No. 3, pp. 131-150.

Stanley, T.D. and Jarrell, S.B. (1989), "Meta-regression analysis: a quantitative method of literature surveys", Journal of Economic Surveys, Vol. 3 No. 2, pp. 161-170.

Stanley, T.D. and Jarrell, S.B. (2005), "Meta-regression analysis: a quantitative method of literature surveys", Journal of Economic Surveys, Vol. 19 No. 3, pp. 299-308.

Takamatsu, R. and Favero, L. (2017), "Opacity of financial information, adoption of international standards and legal origins", Review of Business Management, Vol. 19, pp. 594-612.

Timm, A., Santana, V., Costa, I. and Zóboli, F. (2016), "International financial reporting standards and earnings management in Latin America", Revista de Administração Contemporânea, Vol. 20 No. 3, pp. 368-388.

Trimble, M. (2018), “A reinvestigation into accounting quality following global IFRS adoption: evidence via earnings distributions", Journal of International Accounting, Auditing and Taxation, Vol. 33, pp. 18-39.

Wang, Y. and Campbell, M. (2012), "Earnings management comparison: IFRS vs China GAAP", International Management Review, Vol. 8, pp. 5-11.

Anggraeni, M.D. and Wardhani, R. (2017), "The effect of leverage and IFRS convergence on earnings management through real activities manipulation in Asia", Asian Journal of Business and Accounting, Vol. 10, pp. 87-125.

World Justice Project (2018), Rule of Law Index 2017-2018, p. 198. IBSN (print): 978-0-9882846-2-3 IBSN (online): 978-0988284630.

\section{Corresponding author}

Samuel Arturo Mongrut can be contacted at: smongrut@tec.mx
IFRS adoption and firm's opacity 